\title{
МИГРАЦИОННОЕ ДВИЖЕНИЕ НАСЕЛЕНИЯ РЕГИОНОВ СИБИРИ
}

\author{
В. И. Самаруха' 1 , Т. Г. Краснова ${ }^{2}$, Т. Н. Плотникова ${ }^{3}$ \\ 1 Байкальский государственный университет, г. Иркутск, Российская Федерация \\ ${ }^{2}$ Хакасский государственный университет им. Н. Ф. Катанова, Г. Абакан, Российская Федерация \\ ${ }^{3}$ Хакасский технический институт - филиал Сибирского федерального университета, г. Абакан, \\ Российская Федерация
}

Информация о статье

Дата поступления

16 ноября 2017 г.

Дата принятия к печати

28 февраля 2018 г.

Дата онлайн-размещения

30 марта 2018 г.

\section{Ключевые слова}

Миграционная активность регионов; миграционные процессы; миграционное движение; регрессионная модель; миграционная эфрфективность

\begin{abstract}
Аннотация
Миграционные процессы затрагивают интересы населения и в значительной степени влияют на социально-экономическое положение регионов. В Сибири сложилась серьезная ситуация с миграцией жителей в другие регионы России. Стабильный отток коренного населения привел к снижению доли коренных народов. Анализ современного состояния экономики регионов Сибирского федерального округа свидетельствует о зависимости социально-экономических процессов от миграционной активности населения. В статье рассматривается эволюция миграционных потоков в регионах Сибири и характеризуется взаимосвязь между миграционными процессами и социально-экономическим положением регионов. На базе статистических показателей социально-экономической деятельности регионов СФО построена регрессионная модель миграционной активности. Параметры модели подтверждают многофакторную природу миграционных процессов, объясняющих тенденции, происходящие в регионах Сибири.
\end{abstract}

\section{MIGRATION MOVEMENT OF THE POPULATION OF SIBERIAN REGIONS}

\author{
Victor I. Samarukha ${ }^{1}$, Tatyana G. Krasnova2, Tatyana N. Plotnikova ${ }^{3}$ \\ ${ }^{1}$ Baikal State University, Irkutsk, the Russian Federation \\ ${ }^{2}$ Katanov Khakass State University, Abakan, the Russian Federation \\ ${ }^{3}$ Khakass Technical Institute - Branch of Siberian Federal University, Abakan, the Russian Federation
}

Article info

Received

November 16, 2017

Accepted

February 28, 2018

Available online

March 30, 2018

\section{Keywords}

Regional migration activity; migration processes; migration movement; regres-sion model; migration efficiency

\begin{abstract}
Migration processes affect the interests of the population and substantially influence the economic and social situation of regions. In Siberia, there is a serious situation with migration of residents to other regions of Russia. Stable tendencies of outflow of indigenous people have led to a decrease in the share of indigenous people. The analysis of the current state of the economy of the Siberian Federal District regions demonstrates dependence of social and economic processes on the migration activity of the population. The article examines the evolution of migration flows in Siberian regions and describes the interrelation between migration processes and economic and social situation of the regions. The authors constructed a regression model of the migration activity on the basis of statistics of social and economic activity of the Siberian Federal District regions. Parameters of the model confirm the multiple-factor nature of the migration processes that explain the tendencies occurring in regions of Siberia.
\end{abstract}

Проблемы миграционного движения населения регионов Сибири затрагивают интересы всех слоев населения и иллюстрируют их реакцию на социально-экономические, политические и культурные изменения в регионах и стране в целом [1].
С середины 1990-х гг. Сибирь стала терять население из-за его миграции преимущественно в другие регионы России (около $74 \%$ мигрантов) и в другие государства (около $26 \%$ мигрантов) [2]. За последние 25 лет численность населения Сибири снизи- 
лась более чем на 1,5 млн чел., в том числе за счет миграции населения - более чем на 600 тыс. чел. Наибольшие потери (60\%) вызваны превышением смертности над рождаемостью, особенно негативно данная тенденция складывалась с 1995 до 2005 г. [3].

Миграционное сальдо населения Сибири с 1 января 2016 г. по 1 января 2017 г. также не является положительным, несмотря на то что отток населения несколько снизился и в большей степени стал компенсироваться за счет естественного прироста населения (табл. 1). С 2010 г. по настоящее время среднегодовая убыль населения Сибири стабилизировалась на значениях 42-45 тыс. чел. в год. В предшествующий этому периоду 20-летний период она составляла 60-75 тыс. чел. в год [4].

Наибольшая убыль населения фиксировалась либо в регионах с невысокой долей коренного населения (Кемеровская, Иркутская, Омская области, Алтайский край), либо в регионах с незначительными темпами роста промышленного производства (Забайкальский край, Республика Тыва) [5].

Самые высокие темпы убыли населения отмечаются в Иркутской области по причине оттока населения в другие регионы страны. Более глубокий анализ этих процессов выявил, что наиболее значительный отток из региона осуществляется из-за выезда талантливой молодежи в центральные регионы России (Москву, Санкт-Петербург).

Другим регионом - лидером по уровню оттока является Забайкальский край. Здесь иная структура выезжающих: состоявшиеся предприниматели, надеющиеся на более интенсивное развитие бизнеса в других регионах страны, и работоспособное население, выезжающее на поиски лучшего профессионального устройства [5].

В последнее время лидирует пять основных направлений миграции сибиряков в другие регионы России: Москва, Санкт-Петербург, Сочи, Краснодарский край и Новосибирск. Что же касается миграции населения Сибири в другие страны, то на первом месте здесь по-прежнему два государства - Германия и Израиль. В последние десять лет увеличилось количество выезжающих на постоянное место жительства в Таиланд, Чехию, Балканские страны, Австралию, Испанию и Италию [6].

С середины 1990-х гг. наметилась тенденция оттока коренных народов Сибири как в другие регионы страны, так и в другие страны. В табл. 2 представлена структура коренных народов Сибири и тенденции изменения их численности.

Демографические процессы в регионах Сибири

Таблица 1

\begin{tabular}{|c|c|c|c|c|c|}
\hline \multirow[b]{2}{*}{ Субъект РФ } & \multicolumn{2}{|c|}{ Население, чел. } & \multirow{2}{*}{$\begin{array}{c}\text { Средний при- } \\
\text { рост (убыль) } \\
\text { за три года }\end{array}$} & \multirow{2}{*}{$\begin{array}{c}\text { Естественный } \\
\text { прирост (убыль) } \\
\text { за три года }\end{array}$} & \multirow{2}{*}{$\begin{array}{c}\text { Миграционный } \\
\text { прирост (убыль) } \\
\text { за три года }\end{array}$} \\
\hline & $\begin{array}{c}\text { На } 1 \text { января } \\
2016 \text { г. }\end{array}$ & $\begin{array}{c}\text { На } 1 \text { января } \\
2017 \text { г. }\end{array}$ & & & \\
\hline Российская Федерация & 146544710 & 146804372 & 701087 & -6858 & 252804 \\
\hline Сибирский фредеральный округ & 19324031 & 19326196 & -43505 & 44265 & -87770 \\
\hline Красноярский край & 2866490 & 2875301 & 26433 & 11949 & 14484 \\
\hline Новосибирская область & 2762237 & 2779555 & 51954 & 6102 & 45852 \\
\hline Кемеровская область & 2717627 & 2708844 & -36389 & -17270 & -19079 \\
\hline Иркутская область & 2412800 & 2408901 & -21697 & 9741 & -31438 \\
\hline Алтайский край & 2376774 & 2365680 & -39954 & -12479 & -27475 \\
\hline Забайкальский край & 1083012 & 1078983 & -20878 & 7275 & -28153 \\
\hline Томская область & 1076762 & 1078891 & 6387 & 5219 & 1168 \\
\hline Омская область & 1978466 & 1972682 & -15617 & 474 & -16091 \\
\hline Республика Бурятия & 982284 & 984134 & 4995 & 15189 & -10194 \\
\hline Республика Хакасия & 536781 & 537668 & 2661 & 2091 & 570 \\
\hline Республика Алтай & 215161 & 217007 & 5538 & 5247 & -291 \\
\hline Республика Тыва & 315637 & 318550 & 2913 & 11149 & -8236 \\
\hline
\end{tabular}

Источник: [5].

Таблица 2

Структура коренных народов Сибири

\begin{tabular}{|c|r|r|r|}
\hline \multicolumn{1}{|c|}{ Коренные народы Сибири } & $\begin{array}{c}\text { Количество, } \\
\text { чел.* }\end{array}$ & Доля, \% & $\begin{array}{c}\text { Тенденции изменения } \\
\text { с 2000 г. }\end{array}$ \\
\hline $\begin{array}{l}\text { Тюркские (якуты, тувинцы, хакасы, алтай- } \\
\text { цы, шорцы, долганы, сибирские татары, } \\
\text { телеуты, тофралары, чулымцы) }\end{array}$ & 917104 & 57,61 & Уменьшение \\
\hline
\end{tabular}




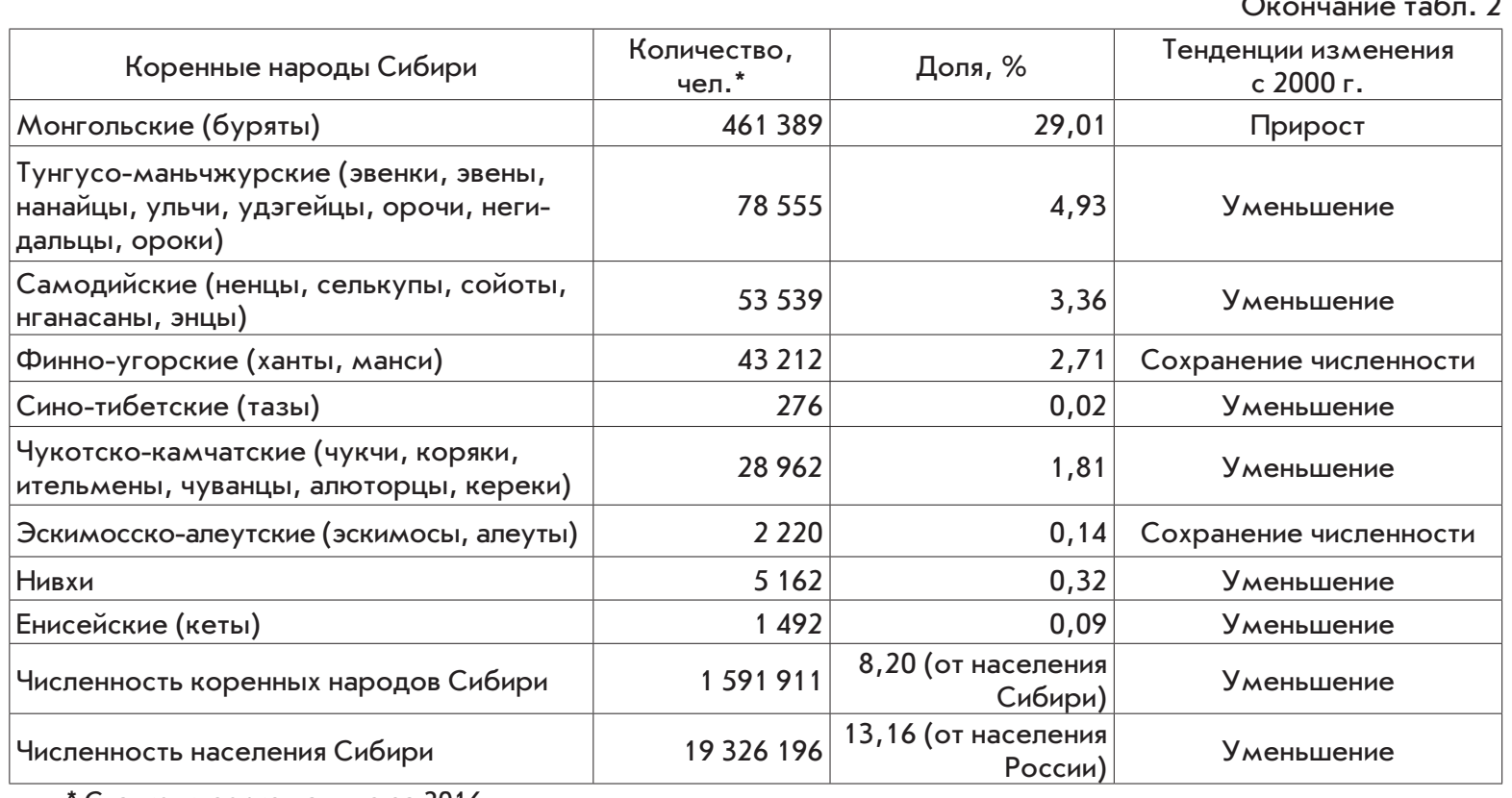

${ }^{*}$ Статистические данные за 2016 г.

Устойчивый прирост наблюдается только по монгольской группе коренных народов Сибири, по финно-угорской и эскимосскоалеутской группам народов зафиксирована тенденция к сохранению численности, а по всем другим группам народов происходит уменьшение [7]. В настоящее время в Сибири проживает 1 591,9 тыс. коренных народов, что составляет 8,2 \% от численности сибиряков, 20 лет назад доля коренных народов была равна 11,3\%. Снижение доли коренных народов, как и абсолютного значения их численности, связано с тремя основными процессами: снижением коэфрфициентов рождаемости, интернационализацией населения (смешанными браками) и оттоком коренного населения Сибири в другие регионы страны и другие государства.

Некоторые ученые считают, что миграция населения выполняет важную функцию, обеспечивая территориальное перераспределение трудовых ресурсов. С этим можно согласиться в случае оттока населения из регионов Сибири в индустриально развивающиеся центры и осваиваемые районы страны (поскольку миграция населения поспособствует более полному использованию рабочей силы, росту производства). Однако последствия миграции в настоящее время противоречивы, поскольку миграционные процессы в Сибири связаны не с перераспределением населения в осваиваемые районы страны, а прежде всего с его отъездом в столицу и развитые центральные регионы России и за рубеж [8].

Зачастую миграционные процессы оказывают положительное влияние на сбалансированность рынка труда в центральных регионах России, поскольку выезжает либо молодежь, либо уверенные в своей профессиональной компетенции граждане. С другой стороны, массовый приток мигрантов может быть причиной роста социальной напряженности: увеличения безработицы, более сильного давления на социальную инфраструктуру (жилье, здравоохранение, транспорт и др.), поэтому миграция иногда негативно влияет на уровень жизни коренных жителей. В то же время миграция населения Сибири ухудшает трудовой потенциал макрорегиона, снижая уровень его конкурентоспособности [9].

Внешняя миграция населения Сибири (международная) связана с пересечением государственной границы. Примерно четвертая часть сибиряков становятся эмигрантами, которые принимают решение либо о длительном, либо о постоянном проживании в других странах. Большое значение для макрорегиона имеет миграция населения "село - город», но с развитием урбанизации повышается роль миграции населения "маленький город - большой город». Центрами притяжения населения по понятным причинам становятся региональные столицы.

Из-за постоянной миграции «село - город" за последние сто лет развития Сибири доля городского населения повысилась с 9,7 \% в 1916 г. до 74, 4 \% в 2016 г. Безусловно, это не могло не отразиться на кадровом потенциале агрокомплекса Сибири [10]. 
Динамика численности городского и сельского населения Сибири

\begin{tabular}{|l|r|r|r|r|r|r|r|r|r|}
\hline \multicolumn{1}{|c|}{ Показатель } & \multicolumn{1}{c|}{1858} & 1916 & 1922 & 1939 & 1945 & 1959 & 1996 & 2002 & 2016 \\
\hline $\begin{array}{l}\text { Население Сибири, } \\
\text { всего, тыс. чел. }\end{array}$ & 2691,5 & 11049,7 & 9265,2 & 14112,0 & 13549,6 & 18040,0 & 21102,0 & 20063,0 & 19320,0 \\
\hline $\begin{array}{l}\text { Сельское населе- } \\
\text { ние, тыс. чел. (\%) }\end{array}$ & 2517,3 & $\begin{array}{r}9974,2 \\
(93,5)\end{array}$ & $\begin{array}{r}8298,1 \\
(90,3)\end{array}$ & $\begin{array}{r}9688,0 \\
(89,6)\end{array}$ & $\begin{array}{r}768,6) \\
(56,7)\end{array}$ & $\begin{array}{r}9326,9 \\
(51,7)\end{array}$ & $\begin{array}{r}6274,0 \\
(29,6)\end{array}$ & $\begin{array}{r}5790,0 \\
(28,5)\end{array}$ & $\begin{array}{r}4945,0 \\
(25,6)\end{array}$ \\
\hline $\begin{array}{l}\text { Городское населе- } \\
\text { ние, тыс. чел. (\%) }\end{array}$ & $\begin{array}{r}174,2 \\
(6,5)\end{array}$ & $\begin{array}{r}1075,5 \\
(9,7)\end{array}$ & $\begin{array}{r}967,1 \\
(10,4)\end{array}$ & $\begin{array}{r}4424,0 \\
(31,4)\end{array}$ & $\begin{array}{r}5860,3 \\
(43,3)\end{array}$ & $\begin{array}{r}8713,1 \\
(48,3)\end{array}$ & $\begin{array}{r}14855,0 \\
(70,4)\end{array}$ & $\begin{array}{r}14273,0 \\
(71,5)\end{array}$ & $\begin{array}{r}14374,1 \\
(74,4)\end{array}$ \\
\hline
\end{tabular}

*1996, 2002, 2016 гг. - без Тюменской области.

Источники: $[4 ; 5]$.

Самыми благоприятными для заселения макрорегиона были следующие периоды: 1858-1916 гг., когда население Сибири возросло с 2,7 млн до 11,0 млн чел. (в 4,1 раза), и 1941-1996 гг., когда население увеличилось с 13,5 млн до 21,1 млн чел. (прирост 64 \%). Первый период заселения был связан с реформами П. А. Столыпина и сельскохозяйственным освоением, а второй - с индустриальным освоением Сибири. Благодаря аграрной реформе П. А. Столыпина осуществлялось самое массовое в истории России переселение малоземельных крестьян на казенные земли в малообжитых районах Урала и Сибири.

Большинство из этих крестьян были русские, но также встречались большие группы переселенцев из малороссийских губерний, белорусских земель, чуваши, мордва. Немаловажное значение в формировании современной этнической карты Сибири имели принудительные миграции. Например, почти все живущие в Сибири финны, поляки, литовцы, латыши, эстонцы - это потомки ссыльных. Более 75 \% немцев в сибирском макрорегионе - это потомки депортированных в 1941 г. немцев Поволжья [11].

Важная волна переселений связана с эвакуацией в Сибирь во время Великой отечественной войны стратегически важных производств, а также специалистов, многие из которых здесь и осели. Через некоторое время (в 1950-1980-е гг.) началось мощное индустриальное освоение Сибири, которое привело к активной миграции населения со всей страны в этот макрорегион. Наибольший приток населения в этот период осуществлялся за счет всесоюзных строек, освоения нефтяных и газовых месторождений. Следует отметить, что в Сибири, не знавшей массового голода, масштабных эпидемий, боевых действий, всегда был достаточно высоким и естественный прирост населения. Большинство было занято в промышленности, работавшей на оборону и космос, сельском хозяйстве, во всех крупных городах были открыты университеты, в Новосибирске был создан современный Академгородок. Мигранты ехали в Сибирь в основном на заработки, поскольку зарплата здесь была существенно выше. Многие оставались, потому что уровень жизни принципиально не отличался от уровня жизни в других регионах России, а рабочие места были в достатке.

Но в 1990-е гг. ситуация изменилась. В результате приватизации предприятий произошло сокращение численности рабочих мест, люди в массовом порядке начали уезжать из Сибири, и сальдо миграции стало отрицательным.

Лучшее по миграционным показателям положение было в Новосибирской области, где существует положительное сальдо миграции. Это объясняется тем, что Новосибирск - центр Сибирского федерального округа, обладающий высоким уровнем обеспеченности производственным, образовательным, научным и иными потенциалами, что притягивает население. Томск, Новосибирск и Иркутск являются студенческими столицами Сибири, принимая большое количество молодых людей, которые поступают сюда в университеты, что несколько улучшает их миграционный фон.

Довольно значительный вклад в снижение численности населения внесли этнические миграции. Программы репатриации, принятые в Германии, Израиле, Греции, Польше, странах Прибалтики, вызвали волну эмиграции [12].

В то же время в связи с суровым климатом Сибирь постоянно привлекала к себе внимание и коммерческий интерес людей из теплых союзных республик (а впоследствии независимых государств) - Армении, Грузии, Азербайджана, Молдавии, Киргизии, Казахстана, Таджикистана. Эти мигранты традиционно занимались торговлей, вначале овощами, фруктами и цветами, а дальше товарный ассортимент существенно расширился. Кроме торговли, очень большое количество мигрантов из других стран работает в дорожной отрасли и строительстве. С сере- 
дины 1990-х гг. к ним прибавились китайцы, которые помимо названных сорер деятельности стали активно заниматься сбором дикоросов и сельским хозяйством. К сожалению, многие из вышеназванных мигрантов долгие годы были на нелегальном положении, в последние годы в этой сфере государство начало наводить порядок.

Основными причинами миграции населения из Сибири в последнее десятилетие стали:

- стремление людей к улучшению качества и условий жизни (социальной инфраструктуры);

- поиск трудоустройства в организации с более высокой оплатой труда, на перспективные должности, по специальности;

- потребность в получении и расширении знаний (многие абитуриенты с высокими баллами ЕГЭ едут в Москву и Санкт-Петербург для получения образования);

- ухудшение экологической обстановки в месте проживания;

- необходимость в изменении климатических условий по состоянию своего здоровья или здоровья родственников и близких людей (многие сибиряки стремятся переезжать в регионы, приближенные к Черному или Каспийскому морю);

- объединение с живущими в других регионах родственниками, вступление в брак;

- ухудшение условий трудовой деятельности, развитие конфлликтных ситуаций на работе;

- случайные обстоятельства и другие причины.

На характер и особенности миграционных связей в регионах Сибири очень сильно влияет усиление диффреренциации уровня и качества жизни в различных регионах и поселениях России, открытость внешних для страны границ. Сейчас на федеральном уровне разрабатываются достаточно серьезные региональные программы, которые должны упорядочить миграционные потоки, а самое главное - снизить материальные и моральные издержки самих мигрантов. Потенциальные переселенцы должны заранее получать объективную информацию о состоянии рынка труда и о возможностях решения жилищных проблем на территории вселения и, соответственно, принимать взвешенное решение о перемещении в тот или иной регион России. В настоящее время все это происходит стихийно, с большими издержками как для территорий выезда и вселения, так и для самих мигрантов.

Подводя итоги, можно говорить о том, что фоормирование нового режима миграци- онных связей и потоков миграции в регионах Сибири является новым вызовом для устойчивого стабильного развития макрорегиона. Причины миграции в этом макрорегионе связаны, с одной стороны, с особенностями формирования населения, сложившимися в прошлом, например тем, что динамика прироста численности населения Сибири в значительной степени определялась структурой и характером размещения производительных сил в макрорегионе, а с другой - с отсутствием системы продуманных мер миграционной политики.

Для формирования грамотной миграционной политики требуется детальная оценка миграционного движения. Разработка модели миграционного движения представляется важнейшим условием формирования целенаправленной миграционной политики в регионах. Миграционные процессы воздействуют на все стороны жизни населения экономические, социальные, политические, морально-психологические.

С учетом положительных и отрицательных сторон миграционного движения в модель должны войти социально-экономические показатели функционирования региона. Как уже отмечалось ранее, миграция вызывает определенную напряженность на рынке труда, жилья, в окружающей природной среде, коммунальном хозяйстве, в сфрере социальной защиты, а также в сфере правонарушений. Следовательно, важным условием управления миграционными процессами выступает учет миграционных фракторов в социально-экономической модели развития региона.

Математические методы позволяют наиболее полно анализировать воздействие миграционных процессов на функционирование регионов. Сложные и многофракторные процессы, происходящие на уровне регионов, в значительной степени определяют миграционное движение. С помощью моделирования уровня миграционной активности (за миграционную активность принят коэфффициент миграционного прироста) можно получить модель социально-экономического миграционного эфффекта.

На базе статистических показателей социально-экономической деятельности регионов СФО выполнено моделирование уровней миграционной активности по следующим факторам:

$x_{1}$ - удельный вес экономически активного населения, \%;

$x_{2}$ - удельный вес молодежи в общей численности населения, \%; 
$x_{3}$ - объемы ВРП на душу населения, млн р./чел.;

$x_{3}$ - объемы производства, тыс. р.;

$x_{4}$ - жилая площадь, приходящаяся на 1 чел., $\mathrm{M}^{2} /$ чел.;

$x_{4}$ - объем социальных выплат на душу населения, тыс. р./чел.;

$x_{5}$ - обеспеченность населения врачами в расчете на тысячу населения;

$x_{6}$ - среднемесячная заработная плата, р.;

$x_{7}$ - число мест в детских учреждениях;

$x_{8}$ - коэффициент демографической нагрузки;

$x_{9}$ - число образовательных учреждений среднего образования;

$x_{10}$ - заболеваемость на тысячу населения;

$x_{11}$ - число зарегистрированных преступлений на 100 тыс. населения;

$x_{12}$ - оборот розничной торговли на душу населения, чел.;

$x_{13}$ - объем платных услуг на душу населения;

$x_{14}$ - объем инвестиций в основной капитал на душу населения, р.

Для определения степени влияния факторов была построена модель множественной регрессии: $y=a_{0}+a_{1} x_{1}+a_{2} x_{2}+\ldots+a_{14} x_{14}$ где $у$ - показатель миграционной активности (коэффрициент миграционного прироста); $x_{1}, \ldots, x_{14}$ - фракторы, влияющие на миграционную активность; $a_{0}, a_{1}, \ldots, a_{14}$ - коэффиициенты уравнения регрессии, объясняющие индивидуальные эфффекты от фракторов влияния.

Для построения уравнения регрессии использовались данные за десятилетний период (с 2006 по 2016 г.). В результате расчетов уравнение регрессии имеет следующий вид: $y=-121,61-13,33 x_{1}-42,28 x_{2}+$ $+56,72 x_{3}+19,11 x_{4}+28,14 x_{5}+69,63 x_{6}+$ $+18,9 x_{7}+15,15 x_{8}+3,69 x_{9}-64,72 x_{10}-$ $-5,26 x_{11}+20,44 x_{12}+6,79 x_{13}+49,37 x_{14}$.

Для оценки параметров регрессии были определены коэффициенты регрессии и значимость фракторов миграционной эффрективности.

Анализируя полученные результаты, можно сделать вывод, что миграция имеет многофракторную природу, объясняющую сложность миграционных процессов и их социально-экономическую зависимость.

На базе полученной регрессионной модели по степени миграционной активности можно судить о степени напряженности в регионах, связанных с процессами миграции.

\section{СПИСОК ИСПОЛЬЗОВАНнОЙ ЛИТЕРАТУРЫ}

1. Герасимова О. А. Актуальные проблемы миграции: аналитический обзор / О. А. Герасимова, Л. В. Иванова, Е. В. Заверткина. - Домодедово : ВИПК МВД России, 2014. - 26 с.

2. Плюснин Ю. М. Население в период трансформации жизни в России / Ю. М. Плюснин, А. А. Гордиенко. - Новосибирск, 1997. - 167 с.

3. Соболева С. В. Демографические проблемы Сибири (1990-1995 гг.). Стратегия семейной политики: постановка проблем и пути их решения / С. В. Соболева. - Новосибирск, 1995. - 218 с.

4. Население // Историческая энциклопедия Сибири : в 3 т. / под ред. В. И. Молодина. - Новосибирск, 2009. - Т. 2 : К - Р. - С. 434-441.

5. Регионы России. Социально-экономические показатели / под ред. С. Н. Егоренко [и др.] ; Росстат. M., 2016. - 1326 c.

6. Вакуленко Е. С. Миграционные процессы в городах России: эконометрический анализ / Е. С. Вакуленко // Прикладная эконометрика. - 2012. - № 1 (25). - С. 25-50.

7. Куликова Ю. А. Закономерности процесса трудовой миграции в регионах Сибири / Ю. А. Куликова / / Труды Братского государственного университета. Сер.: Экономика и управление. - 2015. - Т. 1. С. $156-159$.

8. Соболева С. В. Миграция населения в приграничных регионах Сибири / С. В. Соболева, Н. Е. Смирнова, О. В. Чудаева // ЭКО. - 2014. - № 8 (482). - С. 18-31.

9. Кулешов В. В. Проблемы миграции и демографии в Сибири / В. В. Кулешов / / Безопасность Евразии. - 2004. - № 1. - С. 76-86.

10. Леденёва В. Ю. Модели социальной адаптации и интеграции трудовых мигрантов / В. Ю. Леденёва. - М. : Спутник +, 2014. - 144 с.

11. Вакуленко Е. С. Опыт моделирования миграционных потоков на уровне регионов и муниципальных образований РФ / Е. С. Вакуленко, Н. В. Мкртчян, К. К. Фурманов // Научные труды ИНП РАН. 2011. - № 9. - С. 431-450.

12. Бараненкова Т. А. Миграция населения и освоение регионов Сибири и Дальнего Востока / Т. А. Бараненкова // Федерализм. - 2013. - № 4. - С. 99-108.

\section{REFERENCES}

1. Gerasimova O. A., Ivanova L. V., Zavertkina E. V. Aktual'nye problemy migratsii: analiticheski iobzor [Contemporary Issues of Migration: Analytical Review]. Domodedovo, VIPK MVD Rossii Publ., 2014. 26 p.

2. Plyusnin Yu. M., Gordienko A. A. Naselenie $v$ period transformatsii zhizni v Rossii [Population in the Period of Life Transformations in Russia]. Novosibirsk, 1997. $167 \mathrm{p}$. 
3. Soboleva S. V. Demograficheskie problemy Sibiri (1990-1995 gg.). Strategiya semeinoi politiki: postanovka problem i puti ikh resheniya [Demographic Issues of Siberia (1990-1995). Family Policy Strategy: Articulation and Solution of the Problem]. Novosibirsk, 1995. 218 p.

4. Population. In Molodin V. I. (ed.). Istoricheskaya entsiklopediya Sibiri [Encyclopedia of History of Siberia]. Novosibirsk, 2009, vol. 2, pp. 434-441. (In Russian).

5. Egorenko S. N. (ed.). Regiony Rossii. Sotsial'no-ekonomicheskie pokazateli [Regions of Russia. Social and Economic Indicators]. Moscow, 2016. 1326 p.

6. Vakulenko E. Migration in Russian Cities: Econometric Analysis. Prikladnaya ekonometrika = Applied econometrics, 2012, no. 1 (25), pp. 25-50. (In Russian).

7. Kulikova Yu. A. Regularities of Labor Migration in the Regions of Siberia. Trudy Bratskogo gosudarstvennogo universiteta. Seriya: Ekonomika I upravlenie = Proceedings of Bratsk State University. Series: Economics and Management, 2015, vol. 1, pp. 156-159. (In Russian).

8. Soboleva S. V., Smirnova N. E., Chudaeva O. V. Population Migration in the Border Regions of Siberia. $E K O=E C O, 2014$, no. 8 (482), pp. 18-31. (In Russian).

9. Kuleshov V. Problems of Migration and Demography in Siberia. Bezopasnost' Evrazii = Safety of Eurasia, 2004, no. 1, pp. 76-86. (In Russian).

10. Ledeneva V. Yu. Modeli sotsial'noi adaptatsii i integratsii trudovykh migrantov [Models of Social Adaptation and Integration of Labour Migrants]. Moscow, Sputnik + Publ., 2014. 144 p.

11. Vakulenko E. S., Mkrtchyan N. V., Furmanov K. K. Modeling of Migration Flows between RF Regions and Municipalities. Nauchnye trudy: Institut narodnokhozyaistvennogo prognozirovaniya RAN = Scientific Articles Institute of Economic Forecasting Russian Academy of Sciences, 2011, no. 9, pp. 431-450. (In Russian).

12. Baranenkova T. A. Population Migration and the Development of the Regions of Siberia and the Far East. Federalism, 2013, no. 4, pp. 99-108. (In Russian).

\section{Информация об авторах}

Самаруха Виктор Иванович - доктор экономических наук, профессор, кафедра налогов и таможенного дела, Байкальский государственный университет, 664003, г. Иркутск, ул. Ленина, 11, e-mail: SamaruhaVI@bgu.ru.

Краснова Татьяна Григорьевна - доктор экономических наук, профессор, ректор, Хакасский государственный университет им. Н. Ф. Катанова, 655017, Республика Хакасия, г. Абакан, пр. Ленина, 92, e-mail: rector@khsu.ru.

Плотникова Татьяна Николаевна - кандидат экономических наук, доцент, заместитель директора по научным исследованиям и международным связям, Хакасский технический институт - филиал Сибирского федерального университета, 655017, Республика Хакасия, г. Абакан, ул. Щетинкина, 27, e-mail: tnplot@mail.ru.

\section{Для цитирования}

Самаруха В. И. Миграционное движение населения регионов Сибири / В. И. Самаруха, Т. Г. Краснова, Т. Н. Плотникова // Известия Байкальского государственного университета. - 2018. - T. 28, № 1. - C. 56-62. - DOI: $10.17150 / 2500-2759.2018 .28(1) .56-62$.

\section{Authors}

Victor I. Samarukha - DSc in Economics, Professor, Department of Taxation and Customs, Baikal State University, 11 Lenin St., 664003, Irkutsk, the Russian Federation, e-mail: SamaruhaVl@bgu.ru.

Tatyana G. Krasnova - DSc in Economics, Professor, Rector of Katanov Khakass State University, 92 Lenin Avenue, 655017, Abakan, the Russian Federation, e-mail: rector@khsu.ru.

Tatyana N. Plotnikova - PhD in Economics, Associate Professor, Deputy Director on Research and International Relations, Khakass Technical Institute Branch of Siberian Federal University, 27 Schetinkin St., 655017, Abakan, the Russian Federation, e-mail: tnplot@mail.ru.

\section{For citation}

Samarukha V. I., Krasnova T. G., Plotnikova T. N. Migration Movement of the Population of Siberian Regions. Izvestiya Baykal'skogo gosudarstvennogo universiteta $=$ Bulletin of Baikal State University, 2018 , vol. 28, no. 1, pp. 56-62. DOI: $10.17150 / 2500-$ 2759.2018.28(1).56-62. (In Russian). 